\title{
DIRETRIZES PARA O DESENVOLVIMENTO DE LIVROS INFANTIS MULTIFORMATO ACESSÍVEIS
}

\author{
Guidelines for the development of accessible multi-format children's book
}

CARDOSO, Eduardo; Universidade Federal do Rio Grande do Sul

eduardo.cardoso@ufrgs.br

MARTINS, Daianne Serafim; Universidade Federal do Rio Grande do Sul

daiseramart@gmail.com

KAPLAN, Lúcia; Graduanda; Universidade Federal do Rio Grande do Sul

luciakaplan92@gmail.com

\section{Resumo}

Esta pesquisa consiste em estudar técnicas e formatos de publicações de literatura infantil multiformato que visem promover a inclusão de crianças com deficiência e/ou com transtornos do desenvolvimento da linguagem e da comunicação. A partir do embasamento teórico e metodológico, foi realizada a análise de uma seleção de livros infantis multiformato acessíveis disponíveis no mercado para a proposição de diretrizes no desenvolvimento de diferentes formatos e suas versões, tais como: impresso em tinta, em fonte ampliada, em Braille, audiolivro com audiodescrição, audiovisual com audiodescrição, libras e legendas, escrita simples e com sinais.

Palavras Chave: design; acessibilidade; publicação multiformato; literatura infantil.

\begin{abstract}
This research consists of studying techniques and formats of publications for multiformat children's literature that aim to promote the inclusion of children with disabilities and / or language and communication developmental disorders. Based on the theoretical and methodological basis, it was carried out the analysis of a selection of accessible multi-format children's books available in the market to propose guidelines for the development of different formats and versions, such as: printed in ink, enlarged font, Braille, audiobook with audiodescription, audio-visual with audio description, sign language with subtitles and simplified writing with signs.
\end{abstract}

Keywords: design; accessibility; multiformat publication; children literature 


\section{Introdução}

Segundo Bergström (2009), a base de toda a comunicação é o fato de alguém, um emissor, ter algo a dizer (uma mensagem) a outro alguém, um receptor. 0 objetivo do emissor é exercer influência pela emoção, motivação ou informação, e a mensagem é adaptada a esse propósito. Para que isto ocorra, deve-se estabelecer um canal entre o emissor e receptor: o código e o meio. Assim, o emissor espera que a mensagem gere conhecimento, interesse e, finalmente, uma ação. Desta forma, a comunicação, modo natural de socialização entre as pessoas, tem sido uma importante via de expressão do conhecimento humano.

As pessoas com deficiência têm direito à meios de comunicação acessíveis como prevê o contexto legal vigente e a Lei Brasileira de Inclusão - LBI (Lei no 13.146/2015) que entrou em vigor em 03 de janeiro de 2015, representa novo marco sobre as questões envolvendo a igualdade, como vê-se nos artigos abaixo:
I - a bens culturais em formato acessível;
II - a programas de televisão, cinema, teatro e outras atividades culturais e
desportivas em formato acessível;
Art. 42. A pessoa com deficiência tem direito à cultura, ao esporte, ao turismo e ao lazer em igualdade de oportunidades com as demais pessoas, sendo-lhe garantido o acesso:
Art. 67. Os serviços de radiodifusão de sons e imagens devem permitir o uso dos
seguintes recursos, entre outros:
I - subtitulação por meio de legenda oculta;
II - janela com intérprete da Libras;
III - audiodescrição.

Os recursos de comunicação citados também são apresentados em diferentes normas técnicas da Associação Brasileira de Normas Técnicas (NBR16452 - Acessibilidade na comunicação - Audiodescrição; NBR 15599 - Acessibilidade - Comunicação na prestação de serviços; NBR 15290 - Acessibilidade em comunicação na televisão) e salientam a importância de relacionar os elementos de uma abordagem de comunicação integrada e inclusiva para promoção da informação e autonomia para todos. Assim, se faz necessário estudar as estratégias e formas de comunicação e como isso afeta a recepção, a interpretação e a cognição do usuário.

Para as pessoas com transtornos de desenvolvimento da linguagem e da comunicação, que apresentam dificuldade em se comunicar por meio da fala ou da escrita, são utilizados os Sistemas Aumentativos e Alternativos de Comunicação (SAAC), que são formas de comunicação que complementam, suplementam e/ou substituem a fala, por meio de técnicas, ajudas, estratégias e capacidades utilizadas pela pessoa com dificuldade de comunicação (CAMPOS e COSTA, 2013).

É na infância que a criança adquire a linguagem, e o seu domínio possibilita que o indivíduo adquira a capacidade de comunicação, possibilitando a expressão de suas próprias ideias e necessidades, aumentando, assim, a sua participação como cidadão (DUARTE, 2017). Segundo Duarte (2017, p. 222), "A inclusão social e a conquista da cidadania passam pela educação e sua porta de entrada é a aprendizagem da leitura e da escrita." Portanto, a educação pode ser um ponto de partida para que as pessoas com deficiência sejam incluídas na sociedade. Assim, este 
trabalho pretende contribuir para o desenvolvimento de uma publicação de literatura infantil multiformato que atenda às necessidades e desejos de crianças com deficiência e com transtornos de desenvolvimento da linguagem e da comunicação.

\section{Objetivos}

Considerando a contextualização exposta, tem-se como objetivo da pesquisa realizar uma análise de similares a partir dos fundamentos teóricos da área para a elaboração de diretrizes para o desenvolvimento de projetos de publicações de literatura infantil multiformato acessíveis. Para tanto, elencam-se alguns objetivos específicos: caracterizar o público-alvo; compreender os fundamentos de design e de publicações multiformato, assim como os processos de produção e disponibilização de recursos de comunicação acessíveis.

\section{Método}

Para o desenvolvimento da pesquisa foram realizados os seguintes procedimentos metodológicos: (1) Pesquisa para a caracterização do público alvo; (2) Pesquisa acerca dos fundamentos do Design; (3) Levantamento de possíveis formatos para uma publicação infantil multiformato acessível; (4) Análise dos similares selecionados; e (5) Elaboração das diretrizes para o desenvolvimento de projeto de publicações multiformato acessíveis.

A análise sincrônica visa reconhecer o universo do produto em questão e também é proposta para evitar reinvenções. A comparação e a crítica dos produtos selecionados requerem a formulação de critérios comuns (BONSIEPE et al., 1984). Essa análise pode também ser entendida como um levantamento dos itens disponíveis no mercado no presente momento, enquanto estado da arte. Enquanto critérios para a análise, parte-se da fundamentação teórica elencando os seguintes parâmetros: acerca do suporte; da linguagem visual; e dos recursos de acessibilidade.

Para a referida análise foram selecionados cinco livros de literatura infantil escritos ou traduzidos para a língua portuguesa disponíveis no mercado. Assim, busca-se obter uma amostra de diferentes formatos em relação aos recursos de acessibilidade e de diferentes técnicas de produção. Os livros selecionados são: Piu Caganita; O Pequeno Príncipe; A História da Gaivota e do Gato que a Ensinou a Voar; Adélia Sonhadora e O Livro Negro das Cores.

A partir dessa análise e das relações estabelecidas entre os parâmetros de comparação, foram elencados os formatos e versões a serem empregados, assim como diretrizes enquanto parâmetros norteadores para o desenvolvimento de projeto de publicações multiformato acessíveis, segundo uma abordagem integrada e para todos os públicos, incluindo as crianças com deficiência.

\section{Fundamentação teórica}

A fundamentação teórica está dividida segundo os objetivos específicos da pesquisa, tais como: caracterizar o público-alvo; compreender os fundamentos de design, focando no desenvolvimento de livros infantis e no desenho universal; e verificar a relação entre os princípios da comunicação alternativa e o uso de publicações multiformato, assim como os seus processos 
de produção e disponibilização. Estes pontos servem assim como base para a análise de similares proposta.

\subsection{Caracterização do Público}

No que diz respeito ao desenvolvimento psicológico humano, o psicólogo Lev Vygotsky (1896-1934) procurou compreender a origem da inteligência humana e das relações entre desenvolvimento e aprendizagem a partir não somente dos fatores biológicos, mas também dos fatores sócio-históricos. Vygotsky defendia que é preciso estudar a deficiência a partir de um enfoque qualitativo para que seja possível compreender como o desenvolvimento humano se dá diante dessa limitação, uma vez que o funcionamento psicológico se organiza de forma diferente (OLIVEIRA, 1995; NUERNBERG, 2008).

Em relação ao potencial de aprendizagem das crianças, o autor traz o conceito de zona de desenvolvimento proximal, que pode ser definida pela distância entre o nível de desenvolvimento real e o nível de desenvolvimento potencial da criança, ou seja, é a distância à ser percorrida entre o que ela é capaz de fazer de forma autônoma e o que ela é capaz de fazer com a ajuda de alguém. A interação com adultos ou crianças mais experientes evidencia a capacidade da criança de se favorecer a partir do conhecimento do outro (OLIVEIRA, 1995).

A teoria de Vygotsky nos mostra que o aprendizado cria a zona de desenvolvimento proximal, despertando na criança processos internos de desenvolvimento que só são capazes com estímulos externos ao interagir com as pessoas em seu ambiente. Por isso, notamos a importância da educação para as crianças com e sem deficiência, pois o contato com o ambiente escolar propicia o seu desenvolvimento.

Sendo o objetivo do projeto desenvolver uma publicação de literatura infantil multiformato visando promover a inclusão de crianças com diferentes capacidades, serão estudados os indivíduos com transtornos de desenvolvimento da linguagem e da comunicação.

São indivíduos com transtornos de desenvolvimento da linguagem e da comunicação aqueles que não são capazes de se comunicar por meio da fala ou da escrita, ou que tais sistemas de comunicação tradicionais não são suficientes para dar conta de todas as suas funções comunicativas. Entre estes indivíduos, foram selecionados para caracterizar o público-alvo crianças que apresentam o diagnóstico de:(1) Paralisia Cerebral; (2) Deficiência Intelectual; (3) Deficiência Visual; (4) Deficiência Auditiva; (5) Transtornos invasivos do desenvolvimento e (6) Transtornos funcionais específicos.

Considerando o público citado anteriormente, é válido ressaltar que a convenção de pessoas com deficiência, de 2008, reconhece que "a deficiência é um conceito em evolução e que a deficiência resulta da interação entre pessoas com deficiência e as barreiras devidas às atitudes e ao ambiente que impedem a plena e efetiva participação dessas pessoas na sociedade em igualdade de oportunidades com as demais pessoas" (BRASIL, 2008).

Vygotsky (1997 apud NUERNBERG, 2008) defende que as consequências sociais da deficiência acentuam, alimentam e consolidam a própria deficiência, não podendo separar os aspectos biológicos dos aspectos sociais. A teoria de Vygotsky e o preâmbulo da convenção de pessoas com deficiência nos mostram que as condições sociais do indivíduo são determinantes para seu desenvolvimento. 


\subsection{Fundamentos de design}

É por meio do livro infantil que a criança tem o primeiro contato com a linguagem escrita, primeiramente mediada por um adulto, e a medida que ganha domínio sobre a linguagem, pode explorar o mundo dos livros com autonomia. O livro infantil deve atrair para ser descoberto pela criança e é nesse sentido que o projeto gráfico tem um papel essencial.

Neste capítulo, além de fundamentos para o projeto de um livro infantil, serão abordados princípios de Design Universal, considerando que o projeto pretende atender um público diverso com diferentes capacidades e necessidades.

\subsubsection{Design de livros infantis}

Para Lins (2003), o livro infantil deve ser pensado como um todo, envolvendo pesquisa, conhecimento técnico, harmonia entre texto e imagem, sendo resultado de um projeto de design. Serão analisados agora elementos dos livros infantis que devem ser trabalhados de forma integrada, sempre considerando a fase de desenvolvimento e as necessidades educativas especiais das crianças as quais o livro se destina, sendo eles o formato, o suporte, a estrutura, o layout, o texto e a imagem.

Hoje no mercado encontramos uma variedade muito grande de formatos e suportes para livros infantis. Existem livros de pano, madeira, metal e plástico; livros com som, cheiro e textura; livros origami e livros pop-up (LINS, 2003). Para se tomar uma decisão a respeito de qual o suporte mais adequado, deve-se ter em mente o custo-benefício. $O$ formato do livro muitas vezes pode ser sugerido ou imposto pela editora. Porém, mesmo quando se tem a liberdade de escolher o formato, o designer deve levar em consideração os formatos padrões de papel encontrados no mercado. (LINS, 2003).

No que diz respeito à estrutura e layout do livro infantil, alguns autores o comparam com o cinema, e dizem que podemos controlar as imagens do livro como um diretor controla a câmera. É possível explorar profundidade de campo ao mover os personagens entre o primeiro e o segundo plano, alterar o "ângulo da câmera", obtendo desde um plano aberto (long shot) até um plano fechado (close-up), representar a imagem de cima para baixo (plongée) ou de baixo para cima (contra-plongée). Tais recursos trazem para o livro a noção de ritmo e movimento, essencial para prender a atenção dos pequenos leitores. (LINDEN, 2011; MCCANNON et al., 2008; SALISBURY, 2004).

Outra estratégia para se criar um bom ritmo para a história é alternar no mesmo livro diferentes tipos de diagramação. Linden (2011) apresenta três tipos de relações entre imagem e texto, que podem ser utilizadas de forma combinada ou utilizadas como padrão ao longo de toda narrativa. São elas as imagens isoladas, que apresentam o texto e a imagem em páginas separadas; as imagens sequenciais, que são uma sequência de imagens articuladas, como nas histórias em quadrinhos; e as imagens associadas, que são imagens que mesclam o texto e a imagem de forma fluida.

Em relação a imagem, Lins (2003, p.48) coloca que "A técnica e o estilo das ilustrações destinadas a literatura infanto-juvenil não necessitam seguir nenhuma norma. A técnica, o estilo, o traço, tudo tem que trabalhar em conjunto, a favor do livro." $O$ autor ainda coloca que "Qualquer técnica é permitida, contanto que esteja conceitualmente embasada e seja passível de 
reprodução dentro da verba estipulada pelo cliente."

Em contrapartida, enquanto a ilustração ocorre de forma mais subjetiva, é preciso ter certos cuidados ao integrá-la com o texto. Lourenço (2011) traz dois conceitos que devem ser levados em consideração ao aplicar o texto nos livros infantis: legibilidade, se referindo a forma das letras e ao seu espaço entrelinhas, entreletras e entrepalavras, e leiturabilidade, que se relaciona com a compreensão do texto.

Para se obter uma boa legibilidade, segundo Lourenço (2011), são mais adequadas tipografias sem serifa, com o espaço entrelinhas grande o suficiente para haver uma diferenciação de uma linha a outra, assim como maior espaço entre letras e entre palavras. Quanto a leiturabilidade, o autor enfatiza a importância de manter poucos caracteres por linha, e poucas palavras por página, para que o leitor mirim sinta que pode realizar a leitura por conta própria e evite a fadiga.

\subsubsection{Design Universal}

Segundo Keates et al. (2000), um grande equívoco que pode ocorrer no processo de desenvolvimento de produto consiste em considerar a deficiência das pessoas e não as suas capacidades, quando estas deveriam ser a maior preocupação. Consequentemente, há uma necessidade de empregar abordagens baseadas nessa compreensão, minimizando assim o impacto de suas deficiências e melhorando a sua qualidade de vida.

Segundo Souza (2011), o Design for All visa permitir igualdade de oportunidades a todos os cidadãos para participar em todos os aspectos da sociedade. Aslaksen (2010) destaca o princípio de igualdade como base para o design para todos.

O Design Universal, pode ser definido como "[...] o projeto de produtos e ambientes para serem utilizados na maior extensão possível por pessoas de todas as idades e capacidades" (STORY; MULLER; MACE, 1998, p. 2, tradução nossa). O seu objetivo é tornar a vida cotidiana mais simples através da prática projetual direcionada a atender às necessidades de todos da maneira mais ampla possível trazendo benefícios para todas as pessoas, independente condição.

The Center for Universal Design (1997 apud STORY; MUELLER; MACE, 1998) elaborou uma série de princípios para a prática do Design Universal, que podem ser aplicados para avaliar os produtos, serviços e ambientes já existentes, orientar os processos projetuais e fornecer informações quanto à usabilidade de produtos e ambientes aos consumidores e profissionais. São eles: (1) Uso igualitário (2) Flexibilidade; (3) Uso simples e intuitivo; (4) Informação perceptível; (5) Tolerância ao erro; (6) Baixo esforço físico e (7) Dimensão e espaço para acesso e interação.

A partir desses princípios e de acordo com Souza (2011), a busca pela igualdade gera três questões acerca de um projeto universal: "condições de uso", que refere-se à capacidade do produto oferecer para todos o mesmo nível de dificuldade em sua utilização; "valor de uso", que entende-se como o atendimento das mesmas necessidades a todos os usuários, sem que seja mais valioso ou necessário a determinado grupo; e "status de uso", onde todos os usuários devem ser percebidos da mesma forma, ou seja, que o produto não implique em estigmatização de algum grupo. Estas questões refletem objetivos que devem ser idealmente promovidos por tal abordagem e só podem ser alcançados pela devida pesquisa e reconhecimento da diversidade de usuários durante a etapa de planejamento do projeto.

Para o usuário, tais princípios implicam em melhorar sua interação com o produto pela 
garantia de desfrutar de ambientes, serviços e produtos sem receber um tratamento discriminatório em função de características pessoais, cumprindo assim o objetivo de reduzir a distância funcional entre os elementos, sejam eles de uso ou do espaço, e as capacidades das pessoas (CAMBIAGHI, 2007).

\subsection{Comunicação Alternativa e Publicações Multiformato}

Para as pessoas com transtornos do desenvolvimento da linguagem e da comunicação, são utilizados os Sistemas Aumentativos e Alternativos de Comunicação (SAAC), que são formas de comunicação que complementam, suplementam e/ou substituem a fala, por meio de técnicas, ajudas, estratégias e capacidades utilizadas pela pessoa com dificuldade de comunicação (CAMPOS e COSTA, 2013).

Se entende como comunicação alternativa, qualquer forma de comunicação diferente da fala utilizada em um contexto de comunicação frente a frente que pode ser utilizada para substituir a fala. A comunicação aumentativa significa uma comunicação complementar ou de apoio a fala, que garante uma forma de comunicação alternativa se a criança não aprende a falar (VON TETZCHNER e MARTINSEN, 2000).

Os SAAC podem beneficiar pessoas que necessitam de um meio de comunicação temporário, facilitar o desenvolvimento da comunicação oral, facilitar o desenvolvimento de habilidades, conceitos, estruturas linguísticas e leitura-escrita, ou ainda podem ser um meio de comunicação permanente para pessoas que não venham a adquirir a fala por algum comprometimento severo (BARBOSA, 2003; VERZONI, 1999).

Levando em consideração a importância do desenvolvimento da linguagem e da comunicação na infância, é imprescindível que as crianças com dificuldades de comunicação tenham acesso ao SAAC desde cedo. Nesse sentido, o livro multiformato pretende aplicar os SAAC, para que todas as crianças tenham acesso a mesma narrativa.

Segundo Francisco (2016), entre os possíveis formatos para publicações multiformato, estão: (1) Audiolivro; (2) Vídeo-livro em Língua de Gestual (sinais); (3) Versão Pictográfica - SPC; (4) impressão/escrita em Braille; (5) Ilustrações impressas em relevo; (6) Descrição de ilustrações/imagens; (7) Escrita Simples e (8) Recriações táteis.

\section{Análise de Similares}

Para a análise, foram selecionados cinco livros de literatura infantil escritos ou traduzidos para a língua portuguesa, buscando obter uma amostra de diferentes formatos em relação a acessibilidade e diferentes técnicas de produção e desmobilização das publicações. Conforme citado, os livros selecionados são: Piu Caganita ${ }^{1}$; O Pequeno Príncipe ${ }^{2}$; A História da Gaivota e do Gato que a Ensinou a Voar ${ }^{3}$; Adélia Sonhadora ${ }^{4}$ e $O$ Livro Negro das Cores $^{5}$ (figura 1).

\footnotetext{
${ }^{1}$ Livro português escrito e ilustrado por Tânia Bailão Lopes.

${ }^{2}$ Livro francês escrito e ilustrado por Antoine de Saint-Exupery, edição acessível no Brasil adaptado por Ana Rosa Bordin Rabello e Carla Simone da Silveira Mauch.

${ }^{3}$ Livro português escrito por Luis Sepúlveda e ilustrado por Sabine Wilharm.

${ }^{4}$ Livro brasileiro escrito por Lia Zatz e ilustrado por Luise Weiss.

${ }^{5}$ Livro venezuelando escrito e ilustrado por Menena Cottin e Rosana Faría.
} 
Figura 1 - Livros selecionados para análise de similares.
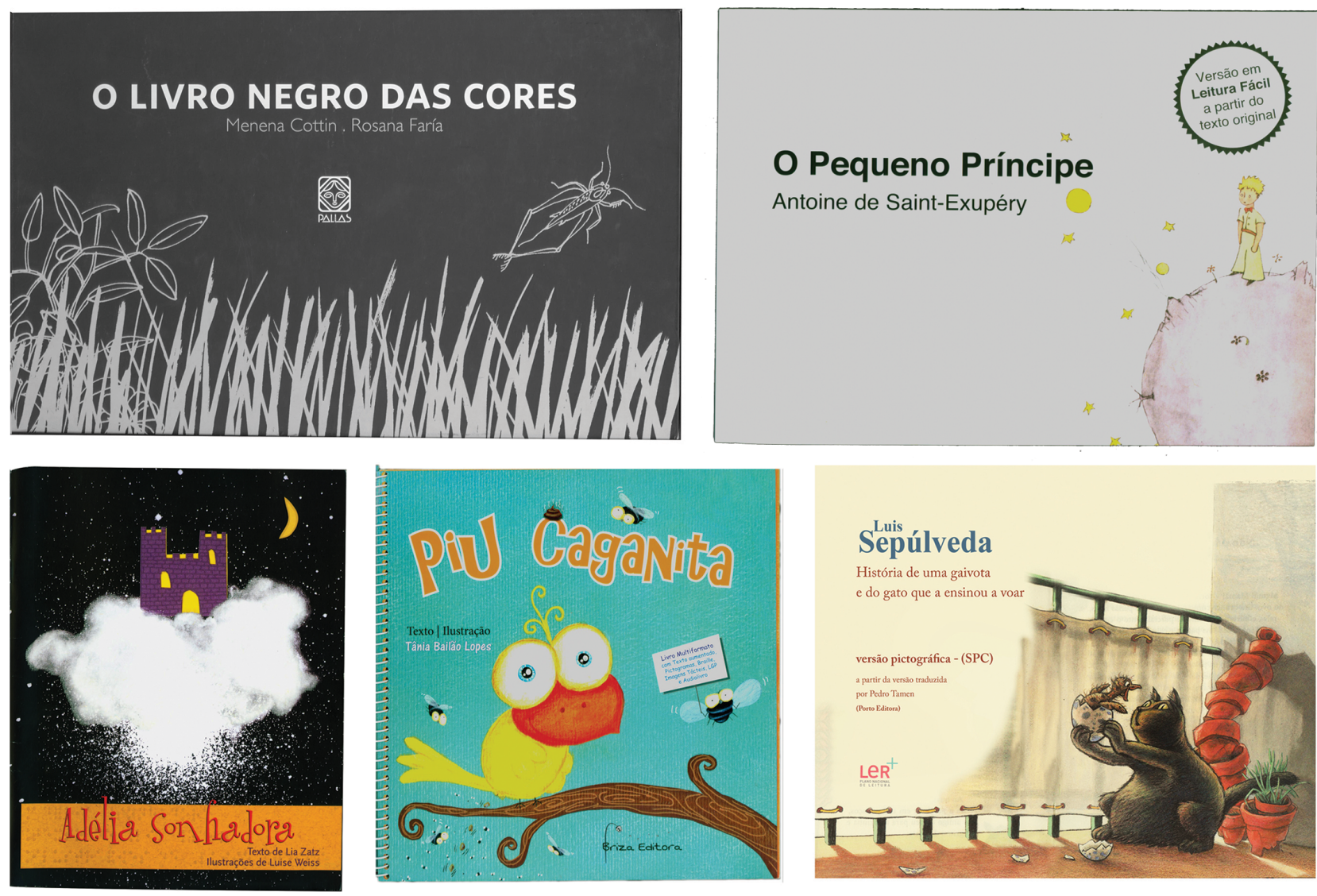

Fonte: acervo dos autores.

Conforme apresentado anteriormente, de acordo com a fundamentação teórica, foram elencados três parâmetros para a análise: suporte, linguagem visual e acessibilidade. Quanto ao suporte foram analisados dados técnicos referentes às dimensões do formato, número de páginas e número de cores; no que diz respeito à linguagem visual foram analisados: formato, tipo de diagramação de acordo com Linden (2011), alinhamento do texto e o entrelinhas; e no que toca a acessibilidade do produto foram analisados: os formatos acessíveis, as técnicas e acabamentos para a produção da imagem tátil, a técnica utilizada para a impressão do braile, janela para Tradutor e Intérprete de Língua de Sinais (TILS) e o uso de pictogramas para comunicação. 
Quadro 1 - Parâmetros acerca do Suporte

\begin{tabular}{|c|c|c|c|c|c|}
\hline & Piu Caganita & $\begin{array}{l}\text { O pequeno } \\
\text { Príncipe }\end{array}$ & $\begin{array}{l}\text { A História da } \\
\text { Gaivota e do Gato } \\
\text { que a Ensinou a } \\
\text { Voar }\end{array}$ & Adélia Sonhadora & $\begin{array}{l}\text { O Livro Negro das } \\
\text { Cores }\end{array}$ \\
\hline Formato & $21 \times 21 \mathrm{~cm}$ & $28,2 \times 21 \mathrm{~cm}$ & $29,7 \times 21 \mathrm{~cm} \mathrm{(A4)}$ & $25 \times 20,5 \mathrm{~cm}$ & $17 \times 28 \mathrm{~cm}$ \\
\hline N. de Páginas & 40 & 120 & 49 & 32 & 28 \\
\hline Papel & $\begin{array}{l}\text { Couchê } 180 \mathrm{~g} / \mathrm{m} \text { e } \\
\text { Offset } 160 \mathrm{~g} / \mathrm{m}\end{array}$ & Offset $120 \mathrm{~g} / \mathrm{m}$ & $\mathrm{n} / \mathrm{a}$ & Couchê $230 \mathrm{~g} / \mathrm{m}$ & $\begin{array}{l}\text { Papel de Cor } \\
180 \mathrm{~g} / \mathrm{m}\end{array}$ \\
\hline Cores & $4 \times 4$ & $4 \times 4$ & $4 \times 0$ & $4 \times 4$ & Cor especial prata \\
\hline
\end{tabular}

Fonte: Vernier, 2018.

Quadro 2 - Parâmetros acerca da Linguagem Visual

\begin{tabular}{|c|c|c|c|c|c|}
\hline & Piu Caganita & $\begin{array}{l}\text { O pequeno } \\
\text { Príncipe }\end{array}$ & $\begin{array}{l}\text { A História da } \\
\text { Gaivota e do Gato } \\
\text { que a Ensinou a } \\
\text { Voar }\end{array}$ & Adélia Sonhadora & $\begin{array}{l}\text { O Livro Negro das } \\
\text { Cores }\end{array}$ \\
\hline Formato & Quadrado & Horizontal & Horizontal & Vertical & Horizontal \\
\hline Diagramação & Associativa & Associativa & Associativa & Dissociativa & Dissociativa \\
\hline Alinhamento & À esquerda & À esquerda & À esquerda & À esquerda & À esquerda \\
\hline Tipografia & Sem serifa & Sem serifa & Sem serifa & Sem serifa & Sem serifa \\
\hline Entrelinha & $1,4 \mathrm{~cm}$ & & & $1,7 \mathrm{~cm}$ & $\mathrm{n} / \mathrm{a}$ \\
\hline
\end{tabular}

Fonte: Vernier, 2018. 
Quadro 3 - Parâmetro acerca da acessibilidade

\begin{tabular}{|c|c|c|c|c|c|}
\hline & Piu Caganita & $\begin{array}{l}\text { O pequeno } \\
\text { Príncipe }\end{array}$ & $\begin{array}{l}\text { A História da } \\
\text { Gaivota e do Gato } \\
\text { que a Ensinou a } \\
\text { Voar }\end{array}$ & Adélia Sonhadora & $\begin{array}{l}\text { O Livro Negro das } \\
\text { Cores }\end{array}$ \\
\hline Formatos & $\begin{array}{l}\text { escrita simples, } \\
\text { SPC, fonte } \\
\text { apliada, braile, } \\
\text { ilustração tátil, } \\
\text { vídeo-livro em } \\
\text { LGP e audiolivro. }\end{array}$ & $\begin{array}{l}\text { leitura fácil, } \\
\text { audiolivro, } \\
\text { descrição das } \\
\text { imagens, vídeo- } \\
\text { livro em Libras e } \\
\text { arquivos de texto } \\
\text { acessíveis. }\end{array}$ & $\begin{array}{l}\text { escrita simples, } \\
\text { SPC, fonte } \\
\text { apliada, arquivos } \\
\text { para impressão } \\
\text { em braile e } \\
\text { ilustração tátil, } \\
\text { vídeo-livro em } \\
\text { LGP e audiolivro. }\end{array}$ & $\begin{array}{l}\text { Braille, ilustração } \\
\text { tátil e fonte } \\
\text { ampliada }\end{array}$ & $\begin{array}{l}\text { Braille e ilustração } \\
\text { tátil }\end{array}$ \\
\hline Imagem tátil & $\begin{array}{l}\text { Contorno com } \\
\text { caneta Setacolor } \\
\text { 3D Brod'Line } \\
602\end{array}$ & $\mathrm{n} / \mathrm{a}$ & $\begin{array}{l}\text { Imagem com } \\
\text { ilustração } \\
\text { simplificada para } \\
\text { download }\end{array}$ & $\begin{array}{l}\text { Verniz U.V., } \\
\text { flocagem e suede }\end{array}$ & Verniz U.V. \\
\hline $\begin{array}{l}\text { Impressão } \\
\text { Braile }\end{array}$ & $\begin{array}{l}\text { Impressão } \\
\text { computadorizada }\end{array}$ & $\mathrm{n} / \mathrm{a}$ & $\begin{array}{l}\text { Arquivos } \\
\text { disponíveis para } \\
\text { impressão } \\
\text { computadorizada }\end{array}$ & Braille.BR® & Serigrafia, verniz \\
\hline TIL & $\begin{array}{l}\text { no canto inferior } \\
\text { esquerdo; há } \\
\text { interferências } \\
\text { com o pano de } \\
\text { fundo }\end{array}$ & $\begin{array}{l}\text { no canto inferior } \\
\text { direito; há pouca } \\
\text { interferências } \\
\text { com o pano de } \\
\text { fundo }\end{array}$ & $\begin{array}{l}\text { no canto superior } \\
\text { esquerdo em um } \\
\text { quadro de fundo } \\
\text { verde; não há } \\
\text { interferências } \\
\text { com o pano de } \\
\text { fundo. }\end{array}$ & $\mathrm{n} / \mathrm{a}$ & $\mathrm{n} / \mathrm{a}$ \\
\hline $\begin{array}{l}\text { Sistema de } \\
\text { Comunicação } \\
\text { Pictórica }\end{array}$ & $\begin{array}{l}\text { Sistema } \\
\text { Pictográfico para } \\
\text { Comunicação }\end{array}$ & $\begin{array}{l}\text { Símbolos } \\
\text { personalizados } \\
\text { com base na } \\
\text { narrativa }\end{array}$ & $\begin{array}{l}\text { Sistema } \\
\text { Pictográfico para } \\
\text { Comunicação }\end{array}$ & $\mathrm{n} / \mathrm{a}$ & $\mathrm{n} / \mathrm{a}$ \\
\hline
\end{tabular}

Fonte: Vernier, 2018.

Assim, a partir da análise realizada, pode-se observar que:

1. Três livros possuem fonte ampliada, sendo acessíveis para a criança com baixa visão;

2. A serigrafia e a impressão offset com matriz gravada são os processos de impressão mais utilizados, tanto para o texto em braile como para as ilustrações em relevo;

3. Dois livros possuem linguagem SPC e um possui versão em leitura fácil com pictogramas personalizados com base na narrativa, sendo acessível para pessoas com deficiência intelectual e demais dificuldades de aprendizagem causadas por transtornos do desenvolvimento da linguagem 
e da comunicação;

4. Três livros possuem versão em Libras com janela para Tradutor e Intérprete de Língua de Sinais (TILS), sendo acessíveis para crianças com deficiência auditiva;

5. A tipografia é na grande maioria sem serifa, legível e possui bom contraste com o fundo, seguindo os princípios de design de livros infantis;

6. Existe uma variedade de formatos e tipos de diagramação e um padrão em relação ao alinhamento do texto à esquerda.

\section{Discussão dos Resultados: Diretrizes de projeto}

A partir dos formatos propostos por Francisco (2016) e com base na análise de similares, foram elaboradas diretrizes a serem seguidas em um projeto de publicação multiformato acessível segundo os seguintes formatos: (1) Sistemas Pictográficos de Comunicação - SPC; (2) Escrita Simples; (3) Versão tátil; (4) Fonte ampliada; (5) Audiolivro e (6) Audiovisual acessível.

\subsection{Sistema de Comunicação Pictórica}

Os símbolos gráficos servem para qualquer pessoa que, de forma temporária ou permanente, tem dificuldades de comunicação. Dentro do público caracterizado, podem se beneficiar desta versão pessoas com paralisia cerebral, síndrome de down e outras deficiências intelectuais, transtorno do espectro autista e outros transtornos invasivos do desenvolvimento, e dislexia.

Entre os sistemas e programas de banco de dados gráficos exististes, indica-se o Boardmaker ${ }^{6}$ e o ARASAAC ${ }^{7}$ : Aragonese - Portal of Augmentative and Alternative Comunication, por se tratar de sistemas flexíveis, podendo ser empregados tanto por pessoas que necessitem utilizar frases curtas como por pessoas que necessitam de um vocabulário mais diversificado e complexo. $O$ programa Boardmaker contém mais de 11.000 símbolos, enquanto o Portal ARASAAC foi desenvolvido pelo Governo da Província de Aragão (Espanha) e disponibiliza um sistema pictográfico de livre distribuição, através da licença Creative Commons. Em ambos sistemas é possível acrescentar, na medida do necessário, fotografias, figuras, números, letras do alfabeto e outros desenhos ou mesmo compartilhar símbolos entre eles. Nesses sistemas, a palavra escrita localiza-se acima ou abaixo de cada pictograma, e o tamanho indicado para a sua aplicação é de aproximadamente $1,9 \mathrm{~cm}$ (VERZONI, 1999).

\subsection{Escrita simples}

A escrita simples consiste na reescrita do texto, mantendo ao máximo o original, simplificando o vocabulário e sintaxe. Assim como na versão SPC, o método de escrita simples podem se beneficiar pessoas com paralisia cerebral, síndrome de down e outras deficiências intelectuais, transtorno do espectro autista e outros transtornos invasivos do desenvolvimento, e dislexia (SOUSA, 2017).

Segundo Souza (2017) existem uma série de regras e parâmetros a serem seguidos para se escrever com método de escrita simples, expostos no quadro 4.

\footnotetext{
${ }^{6}$ https://mayer-johnson.com/

${ }^{7}$ http://www.arasaac.org/
} 
Quadro 4 - Parâmetro para Escrita Simples

\begin{tabular}{ll}
\hline Linguagem & - Fazer um resumo da história dando prioridade à linha narrativa; \\
& - Simplificar a linguagem no vocabulário e sintaxe mantendo o máximo do original; \\
& - Quando necessário, substituir alguns termos, ou expressões, suprimir algumas partes do \\
& texto ou acrescentar outras. \\
& - Usar estrutura simples, com a ordem natural das palavras; \\
& - Evitar frases subordinadas, adjetivos rebuscados e advérbios; \\
& - Dar preferência à voz ativa. \\
\hline Estrutura & - Utilizar frases curtas; \\
& - Colocar vírgulas nas pausas naturais da frase; \\
& - Dividir o texto por linhas, com no máximo 45 caracteres por linha; \\
& - Fazer coincidir o fim natural da frase com o fim da linha; \\
& - Utilizar parágrafos de no máximo 10 linhas. \\
& - Alinhar o texto à esquerda; \\
& - Utilizar espaços entre parágrafos; \\
& - Utilizar espaço entre linhas de 1,5; \\
& - Utilizar letras sem serifa; \\
& - Utilizar letras com corpo não inferior a 12 pt. \\
\hline \multirow{2}{*}{ Formatação } &
\end{tabular}

Fonte: Adaptado de Souza (2017).

\subsection{Versão Tátil}

A versão tátil é formada pela escrita em Braile e pelas ilustrações em relevo. O sistema Braille é um sistema de escrita tátil de pontos em relevo. A escrita em Braille pode ser realizada de três maneiras: através da reglete e do punção, da máquina datilógrafa e por impressoras Braille. A reglete e a punção são mais acessíveis economicamente e são utilizadas para a escrita manual, enquanto as impressoras possibilitam a impressão em larga escala (DALLABRIDA E LUNARDI 2008). Salienta-se ainda respeitar as Normas Técnicas para a produção de textos em Braille disponibilizadas pelo Ministério da Educação, assim como orientações gerais para a sistematização e uso facilitado e/ou intuitivo pelo usuário com deficiência visual (LEMOS, 2006).

Os livros infantis são usualmente repletos de ilustrações visuais, que servem para encorajar a leitura nos leitores mirins, geram o prazer pela leitura e muitas vezes contém detalhes que não estão inclusos no texto. Para crianças com deficiência visual, a ilustração tátil pode ser o meio proporcionar tais interações. Entretanto é importante ressaltar que as ilustrações táteis não reproduzem as imagens visuais, e sim ajudam a comunicar melhor a ideia e informação passada pelo texto (WRIGHT, 2008).

\subsection{Fonte ampliada}

A fonte ampliada deve seguir diretrizes de corpo da letra, com no mínimo de 16 pontos, uma fonte legível sem serifa, como exemplo da fonte Arial, contraste elevado entre fundo e tipografia, número reduzido de caracteres por linha, não ultrapassando 39 caracteres, o kerning deve ser maior, evitando que as letras pareçam juntas e a entrelinha deve ser de 25 a $30 \%$ maior que o corpo do texto (MEÜRER, 2014). 


\subsection{Audiolivro}

O audiolivro é a versão em áudio do texto em conjunto com a audiodescrição, que é uma locução adicional roteirizada. Enquanto as ilustrações táteis servem para gerar interesse e envolvimento da criança com a narrativa, a audiodescrição pode ser utilizada para dar uma noção maior da ideia que está sendo passada por meio visual, fornecendo uma experiência mais completa ao leitor.

Por isso, é interessante integrar recursos sonoros e táteis na narrativa do livro com áudiodescrição das ilustrações, para que a criança tenha todas as ferramentas necessárias para compreensão das formas pela orientação da exploração tátil e consequente compreensão da história no todo.

\subsection{Audiovisual Acessível}

A Lei 10.436 , de 2002, reconhece a Libras como meio legal de comunicação e expressão da comunidade de pessoas surdas no Brasil e diz que deve ser garantido o apoio e difusão da língua como meio de comunicação objetiva e de utilização corrente das comunidades surdas. A lei também diz que a Libras não poderá substituir a modalidade escrita da língua portuguesa (BRASIL, 2002). O ensino de ambas as línguas, oral e gestual, é caracterizada como Filosofia de Educação Bilíngue (CAMPBELL, 2009).

É recomendado que o espaço reservado para a imagem do Tradutor e Intérprete de Língua de Sinais (TILS) fique no canto inferior esquerdo da tela, com o mínimo de interferências visuais como pano de fundo, símbolos ou outras imagens, sem que haja qualquer interrupção ou encobrimento por parte de imagens ou legenda (NAVES, 2015). O vídeo pode também estar acompanhado do texto escrito, em forma de legenda ou fixo no pando de findo, que pode beneficiar as crianças com deficiência auditiva ou com baixa visão.

\section{Considerações Finais}

Os livros de literatura infantil são fundamentais para o desenvolvimento cognitivo e cultural de todos os indivíduos. Uma grande parcela do público infantil com deficiência e transtornos da comunicação e linguagem se beneficia com publicações em formatos acessíveis por meio de comunicação alternativa, promovendo a compreensão e o engajamento com o texto.

Para os educadores, quando o livro é projetado com base no desenho universal, ou seja, já concebido previamente em múltiplos formatos, a preparação das propostas de atividades para uma turma contemplando a diversidade de alunos, torna-se mais fácil, pois o professor não precisará adaptar o livro para que seus alunos com necessidades específicas se envolvam ativamente com a leitura. Do mesmo modo, formatos alternativos possibilitam que cada indivíduo se aproprie do material da maneira que preferir, considerando as diferenças humanas e possibilidades de promoção do aprendizado e socialização.

$\mathrm{Na}$ sequência da pesquisa, espera-se realizar testes de recepção por crianças com deficiência com publicações criadas a partir das diretrizes geradas. Para tanto, necessita-se ainda 
pesquisar e/ou desenvolver protocolos de avaliação para este uso/função. Com os testes esperase avaliar não somente o uso, mas como os processos de produção dos recursos para as publicações.

\section{Referências}

ABNT. Associação Brasileira de Normas Técnicas. NBR 15290: acessibilidade em comunicação na televisão. Rio de Janeiro, 2005. Acesso em novembro de 2017. Associação Brasileira de Normas Técnicas. NBR 16452: acessibilidade em comunicação na comunicação. Rio de Janeiro, 2005. Acesso em novembro de 2017.

ASLAKSEN, F. et al. Universal design: planning and design for all (1997). GLADNET Collection. Paper 327. The Norwe- gian State Council on Disability, Oslo, 1997 . Disponível em: <http://digitalcommons.ilr.cornell.edu/cgi/viewcontent.cgi?article=1329\&context=gladnetcollect $>$ . Acesso em: 21 março de 2014.

BARBOSA, M.H.P. O LIVRO - Instrumento de Comunicação em Crianças com Necessidades Educativas Especiais. Dissertação de Mestrado em Psicologia do Desenvolvimento e da Educação da Criança, Faculdade de Psicologia e Ciência da Educação, Universidade do Porto, 2003

BERGSTRÖM, B. Fundamentos da Comunicação Visual. São Paulo: ed. Rossari, 2009.

BONSIEPE, Gui et al. Metodologia experimental: desenho industrial. Brasília: CNPq/Coordenação Editorial, 1984. BONSIEPE, Gui \& YAMADA, Tamiko. Desenho industrial para pessoas deficientes. Brasília: CNPq /Coordenação Editorial, 1982.

BRASIL. Lei $\mathrm{n} \cong 10.436$, de 24 de abril de 2002. Dispõe sobre a Língua Brasileira de Sinais (LIBRAS) e dá outras providências. Acesso em novembro de 2017.

. Lei n 13. 146, de 06 de julho de 2015, institui a Lei Brasileira de Inclusão da Pessoa com Deficiência (Estatuto da Pessoa com Deficiência). Brasília, DF: 2015. Acesso em novembro de 2017.

Secretaria Nacional de Promoção dos Direitos da Pessoa com Deficiência. Convenção sobre os Direitos das Pessoas com Deficiência. Brasília, 2008.

CAMBIAGHI, Silvana. Desenho Universal: métodos e técnicas para arquitetos e urbanistas. São Paulo: Ed. Senac, 2007.

CAMPBELL, S.I. Múltiplas faces da Inclusão. Rio de Janeiro: Wak Ed., 2009

CAMPOS, F.H.B.; COSTA, M.E. "Vitória, vitória: contou-se uma história": usando um sistema aumentativo e alternativo de comunicação. In: Atas do XII Congresso Internacional GalegoPortuguês de Psicopedagogia, Braga, 2013 pg. 5418-5443

DALLABRIDA, Adarzilse Mazzuco; LUNARDI, Geovana Mendonça. $\mathbf{O}$ acesso negado e a reiteração da dependência: a biblioteca e o seu papel no processo formativo de indivíduos cegos. Cadernos CEDES, Campinas, v. 28, n. 75, p. 191- 208, maio/ago. 2008. Disponível em: <http://www.scielo.br/pdf/ccedes/v28n75/v28n75a04.pdf >. Acesso em: 28 ago. 2017.

DUARTE, N. O professor e o erro no processo de alfabetização. In: SCHOLZE, L.; RÖSING, T.M.K. (Org.). Teorias e práticas de letramento. Brasília: Inep, 2007 
FRANCISCO, M.A.R.M. A Importância do Livro Adaptado em Símbolos Pictográficos da Comunicação no Desenvolvimento de Competências em Crianças com Perturbações na Comunicação. Relatório de projeto, Instituto Politécnico de Leiria, 2016

KEATES, Simeon; CLARKSON, P. John; HARRISON, Lee-Anne; ROBINSON, Peter. Towards a pratical inclusive design approach. Proceedings on the 2000 conference on Universal Usability, Cambridge University, p. 45 - 52, 2000. Disponível em < http://web.mit.edu/16.459/Keates.pdf> Acesso em 20 de fevereiro de 2014.

LEMOS, Edison Ribeiro; CERQUEIRA, Jonir Bechara; MOTA, Maria Gloria Batista; OLIVEIRA, Regina Fátima Caldeira. Normas técnicas para a produção de textos em Braille. Brasília: Ministério da Educação, Secretaria de Educação Especial, 2006.

LINDEN, S.V.D. Para ler o livro ilustrado. São Paulo: Cosac Naify, 2011.

LINS, G. Livro Infantil? : projeto gráfico, metodologia, subjetividade. São Paulo: Edições Rosari, 2003.

LOURENÇO, D.A. Tipografia para livro de literatura infantil: desenvolvimento de um guia com recomendações tipográficas para designers. Dissertação de mestrado apresentada ao programa de Pós- Graduação em Design da Universidade Federal do Paraná, 2011

MCCANNON, D.; THORNTON, S.;WILLIAMS, Y. The Bloomsbury guide to creating illustrated children's books. London: A\&C Black Publishers, 2008.

MEÜRER, M. V.; GONÇALVES, B. S.; CORREIO , V. J. B. Tipografia e baixa visão: uma discussão sobre a legibilidade. Projética, Londrina, V.5 N.2, p. 33 - 46, Dezembro/2014

NAVES, S.B. et al. (Org.). Guia para produções audiovisuais acessíveis. Secretaria do Audiovisual do Ministério da Cultura, 2015

NUERNBERG, A. H. Contribuições de Vygotsky para a educação de pessoas com deficiência visual. Psicologia em Estudo, Maringá, v. 13, n. 2, p. 307- 316, abr/jun. 2008. Disponível em:<http://www.scielo.br/pdf/pe/v13n2/a13v13n2.pdf>. Acesso em: 9 set. 2017.

OLIVEIRA, M. K. Vygotsky: aprendizado e desenvolvimento: um processo sócio-histórico. 2. ed. São Paulo: Scipione, 1995. 111 p. (Pensamento e ação no magistério, v. 21. Mestres da educação).

SOUSA, C. Literatura para todos. In: Curso Cultura e Acessibilidade: pesquisa, formação e produção. Porto Alegre, 2017.

SOUZA, Alexei. Design Universal e Design Inclusivo: transformações para uma aplicação. In: Revista Transverso - diálogos entre design, cultura e sociedade, Barbacena, MG, n. 02, jul. 2011, p. $20-37$.

STORY, Molly; MUELLER, James; MACE, Ronald. The Universal Design File: Designing for People of All Ages and Abilities. Raleigh: NC State University, The Center for Universal Design, 1998.

VERNIER, Carolina. 110f. Publicação multissensorial infantil: enfoque na inclusão de crianças com deficiência visual. Trabalho de conclusão de curso (Graduação em Design Visual) Universidade Federal do Rio Grande do Sul, Porto Alegre, 2018.

VERZONI, L.D.N. Sistema Suplementar e/ou Alternativos de Comunicação. São Paulo: Entre Amigos - Rede de Informações sobre Deficiência, 1999 


\section{Artigo Completo}

VON TETZCHNER, S.; MARTINSEN, H. Introdução à comunicação aumentativa e alternativa. Portugal: Porto Editora, 2000

WRIGHT, S. Guide to Designing Tactile Illustrations for Children's Books. Louisville: American

Printing House for the Blind, 2008. Disponível em:

http://www.aph.org/files/research/illustrations/ 